\title{
A digital mapping application for quantifying and displaying air temperatures at high spatiotemporal resolutions in near real-time across Australia
}

\author{
Mathew Webb ${ }^{\text {Corresp., } 1}$, Budiman Minasny ${ }^{1}$ \\ ${ }^{1}$ School of Life and Environmental Sciences \& Sydney Institute of Agriculture, University of Sydney, Eveleigh, NSW, Australia \\ Corresponding Author: Mathew Webb \\ Email address: mathew.webb@dpipwe.tas.gov.au
}

Surface air temperature $\left(T_{a}\right)$ required for real-time environmental modelling applications should be spatially quantified to capture the nuances of local-scale climates. This study created near real-time air temperature maps at a high spatial resolution across Australia. This mapping is achieved using the thin plate spline (TPS) interpolation in concert with a digital elevation model and 'live' recordings garnered from 534 telemetered Australian Bureau of Meteorology (BoM) automatic weather station (AWS) sites. The interpolation was assessed using cross-validation analysis in a 1-year period using 30-minute interval observation. This was then applied to a fully automated mapping system - based in the $R$ programming language - to produce near real-time maps at sub-hourly intervals. The cross-validation analysis revealed broad similarities across the seasons with meanabsolute error ranging from $1.2^{\circ} \mathrm{C}$ (autumn and summer) to $1.3^{\circ} \mathrm{C}$ (winter and spring), and corresponding root-mean-square error in the range $1.6^{\circ} \mathrm{C}$ to $1.7^{\circ} \mathrm{C}$. The $R^{2}$ and concordance correlation coefficient $\left(P_{c}\right)$ values were also above 0.8 in each season indicating predictions were strongly correlated to the validation data. On an hourly basis, errors tended to be highest during the late afternoons in spring and summer from $3 \mathrm{pm}$ to 6 pm (AEST), particularly for the coastal areas of Western Australia. The mapping system was trialed over a 21-day period from 1 June 2020 to 21 June 2020 with majority of maps completed within 28-minutes of AWS site observations being recorded. All outputs were displayed in a web mapping application to exemplify a real-time application of the outputs. This study found that the methods employed would be highly suited for similar applications requiring real-time processing and delivery of climate data at high spatiotemporal resolutions across a considerably large land mass. 


\section{A digital mapping application for quantifying and}

2 displaying air temperatures at high spatiotemporal

3 resolutions in near real-time across Australia

Mathew Webb ${ }^{1}$, Budiman Minasny ${ }^{1}$

$7 \quad{ }^{1}$ School of Life and Environmental Sciences \& Sydney Institute of Agriculture, The University

8 of Sydney, Eveleigh, NSW, Australia

10 Corresponding Author:

11 Mathew Webb ${ }^{1}$

12167 Westbury Rd, Prospect, TAS, 7250, Australia

13 Email address: mathew.webb@dpipwe.tas.gov.au 


\section{Abstract}

15 Surface air temperature $\left(\mathrm{T}_{\mathrm{a}}\right)$ required for real-time environmental modelling applications should

16 be spatially quantified to capture the nuances of local-scale climates. This study created near 17 real-time air temperature maps at a high spatial resolution across Australia. This mapping is

18 achieved using the thin plate spline (TPS) interpolation in concert with a digital elevation model 19 and 'live' recordings garnered from 534 telemetered Australian Bureau of Meteorology (BoM)

20 automatic weather station (AWS) sites. The interpolation was assessed using cross-validation 21 analysis in a 1-year period using 30-minute interval observation. This was then applied to a fully 22 automated mapping system - based in the R programming language - to produce near real-time 23 maps at sub-hourly intervals. The cross-validation analysis revealed broad similarities across the 24 seasons with mean-absolute error ranging from $1.2^{\circ} \mathrm{C}$ (autumn and summer) to $1.3^{\circ} \mathrm{C}$ (winter and 25 spring), and corresponding root-mean-square error in the range $1.6^{\circ} \mathrm{C}$ to $1.7^{\circ} \mathrm{C}$. The $R^{2}$ and 26 concordance correlation coefficient $\left(P_{c}\right)$ values were also above 0.8 in each season indicating 27 predictions were strongly correlated to the validation data. On an hourly basis, errors tended to 28 be highest during the late afternoons in spring and summer from $3 \mathrm{pm}$ to $6 \mathrm{pm}$ (AEST), 29 particularly for the coastal areas of Western Australia. The mapping system was trialed over a 30 21-day period from 1 June 2020 to 21 June 2020 with majority of maps completed within 2831 minutes of AWS site observations being recorded. All outputs were displayed in a web mapping 32 application to exemplify a real-time application of the outputs. This study found that the methods 33 employed would be highly suited for similar applications requiring real-time processing and 34 delivery of climate data at high spatiotemporal resolutions across a considerably large land mass. 


\section{Introduction}

36 A timely and accurate source of air temperature $\left(\mathrm{T}_{\mathrm{a}}\right)$ data is essential for a wide variety of

37

38

39

40

41

42

43

44

45

46

47

48

49

50

51

52

53

54

55

56

57

58

59

60

61

62

63

64

65

66

67

68

69

70

71

72

73

environmental modelling applications requiring real-time monitoring of environmental change (Lazzarini et al. 2014). This is often gleaned from a network of in-situ telemetered meteorological weather stations that are streamed over the internet (Williams et al. 2011). However, datasets of this nature tend to be relevant for a single geographic location that fail to accurately account for the spatial variability between sites that can vary markedly over short distances (Webb et al. 2016). For applications that rely on location-specific data, observations are often harvested from stations situated kilometers away from their location of interest, resulting in that data not being truly representative of the desired location (Jeffrey et al. 2001; Liu et al. 2018b). Thus, $T_{a}$ can vary considerably over space and time, often attributed to the effects of topographic, coastal and latitudinal factors (Hutchinson 1991; Jarvis \& Stuart 2001a; Wang et al. 2011), cloud cover (Xue et al. 2019), radiative effects from aerosols (Li et al. 2017; Mitchell et al. 1995) and diurnal variation (Liu et al. 2018a). As such, $T_{a}$ for the purpose of input to real-time modelling applications need to be spatially quantified to dynamically account for these interactions but also at an appropriate spatial and temporal resolution to account for the subtle nuances of local-scale climates.

There has been a plethora of research aimed at interpolating surface air temperature at various spatiotemporal scales (Hutchinson 1991; Jarvis \& Stuart 2001b; Jeffrey et al. 2001; Jones et al. 2009; Xu et al. 2018). This is in addition to surface temperature estimated from satellite data (Mao et al. 2017; Sobrino et al. 2020). Or from regional reanalysis of global circulation models at high spatiotemporal resolutions (Bollmeyer et al. 2015; Su et al. 2019). Despite this, their application to real-time monitoring of climate have been limited, or insufficient for local-scale monitoring purposes. For example, a modelling system based on remote sensing data coupled with in-situ meteorological recordings was able to produce air temperature maps in near realtime across the United Arab Emirates (Lazzarini et al. 2014). However, the spatial resolution of $\sim 3 \mathrm{~km}$ was limited in accounting for lapse rates in highly variable topography, despite the system capable of delivering outputs at very high temporal resolution (every 15-minutes). Similarly, a near real-time drought monitoring tool developed for South Asia (Aadhar \& Mishra 2017), capable of producing daily minimum and maximum temperatures at a spatial resolution of $0.05^{\circ}$ $(\sim 5 \mathrm{~km})$, would also require further adaptation for high resolution monitoring. This is in addition to a similar system currently used in Australia, where daily minimum (Tmin) and maximum (Tmax) temperatures are produced from Australian Bureau of Meteorology (BoM) weather station sites using thin plate smoothing spline (TPS) interpolation to deliver daily products at $0.05^{\circ}(\sim 5 \mathrm{~km})$ grid resolution (Jeffrey et al. 2001; Jones et al. 2009). While both datasets are useful for broad-scale analysis requiring up-to-date daily records, they still lacked the resolution for sub-daily real-time monitoring at the local-scale.

Peer) reviewing PDF | (2020:07:50683:1:1:NEW 13 Sep 2020) 
74 Recently, a near-real time mapping system was developed to produce air temperature maps at

75

76

77

78

79

80

81

82

83

84

85

86

87

88

89

90

91

92

93

94

95

96

97

98

99

100

101

102

103

104

105

106

107

108

109

110

111

112

113 high spatiotemporal resolutions across the state of Tasmania, Australia (Webb et al. 2020). This used a combination of regression trees (RT) and TPS interpolation and capable of consistently producing maps at a spatial resolution of $80 \mathrm{~m}$ at 1-hourly time steps. Evaluation of the system showed that the TPS method was highly suited to real-time application due to the speed and relative accuracy of the outputs produced. For example, assessment of the TPS interpolation showed root mean square errors were consistently under $1.5^{\circ} \mathrm{C}$, in addition to only requiring 2minutes processing time to produce each map product. In this context, the application would be suited to the estimation of $\mathrm{T}_{\mathrm{a}}$ across a much larger geographic space at a similar spatiotemporal resolution. As such, there is also an opportunity to apply this approach on a digital platform for real-time access for end-users.

The objective of this study was to apply and extend the methods in Webb et al. (2020) for production of $\mathrm{T}_{\mathrm{a}}$ maps across continental Australia. TPS interpolation is used to produce $\mathrm{T}_{\mathrm{a}}$ maps at sub-hourly intervals (every 30-minutes) based on recordings garnered directly from BoM automatic weather station (AWS) sites. The resulting maps are presented digitally at a spatial resolution of $286 \mathrm{~m}$, appropriate for local-scale monitoring purposes. The methods for prediction accuracy are evaluated using historic hourly $\mathrm{T}_{\mathrm{a}}$ data captured over a 1-year period, in addition to assessing the efficacy of the system for real-time application and subsequent display of outputs in a purpose-built web mapping application.

\section{Materials \& Methods}

\section{Approach}

The present study consisted of 2 parts. Firstly, evaluation of the TPS methodology using crossvalidation; and secondly, application of the methodology for operational real-time mapping of $\mathrm{T}_{\mathrm{a}}$ (Fig. 1). For the evaluation purpose of the study, a historical dataset of 30 -minute interval $\mathrm{T}_{\mathrm{a}}$ recordings was garnered from BoM automatic weather station (AWS) sites for the 1-year period 1 March 2019 to 29 February 2020. This data was used in a leave-one-out cross-validation exercise to assess the prediction performance of the TPS interpolation method. For the application of the methodology for operational real-time mapping, this was tested over a 21-day period from 1 June 2020 to 21 June 2020 . For this purpose, a fully automated mapping system was developed using R programming language (R Development Core Team 2015). Processing performance of this mapping system was evaluated for computational efficiency by analyzing each subsequent spatial output (i.e. the time to taken to produce each $\mathrm{T}_{\mathrm{a}}$ map) and therefore assessed for real-time application. Maps produced from the interpolation process are immediately displayed in a web map application.

\section{Air temperature $\left(T_{a}\right)$ data}

Air temperature $\left(\mathrm{T}_{\mathrm{a}}\right.$ ) data recorded by automatic weather stations (AWS) from the Bureau of Meteorology (BoM) and capable of providing real-time access at 30-minute intervals were 
114 considered for primary use in this study (Fig. 2). For evaluating the accuracy of the model, a

115

116

117

118

119

120

121

122

123

124

125

126

127

128

129

130

131

132

133

134

135

136

137

138

139

140

141

142

143

144

145

146

147

148

149

150

151

152

153

requirement was set, where each station used for the real-time application should have historic recordings for the previous year, specifically from 1 March 2019 to 29 February 2020. These historical data were used for cross-validation analysis. It should be noted that not all AWS sites had data available for the entire evaluation period. Thus, AWS sites that had least 15 days of recordings - consisting of 30-minute interval recordings in each season - was considered for the evaluation process. AWS sites that did not meet this criterion were discarded from the analysis (192 in total). Thus, the screening process resulted in 534 AWS sites corresponding to a possible 17567 recording observations in the evaluation period and relevant to each AWS. It should be noted that AWS air temperature observations are recorded using a resistance temperature detector placed within a Stevenson weather screen at $1.2 \mathrm{~m}$ above ground (Bureau of Meteorology 2018). All AWS recordings are telemetered into the BoM climate database and publicly accessible via URL (http://www.bom.gov.au/tas/observations/). These are typically displayed at 30-minute intervals. However, due to telemetry and processing delays, readings tend to lag the true observation time of approximately 10 - to 20 -minutes.

\section{Interpolating $\mathbf{T}_{\mathrm{a}}$ using thin plate smoothing splines (TPS)}

$T_{a}$ values garnered from the BoM AWS sites were interpolated on a 30-minute interval basis using thin plate smoothing splines. This was performed to form TPS predictions in the evaluation period (1 March 2019 to 29 February 2020) as well as for application to real-time mapping. Its application involves a trivariate approach whereby latitude, longitude, and elevation variables are used as independent variables, as per Jeffrey et al. (2001). The independent variables of latitude and longitude are used for the partial spline component to account for spatial variation, whereas elevation is combined to account for the temperature lapse rates. The spline component of the algorithm is optimised by minimising the generalized cross validation error from the residual sum of squares (Hutchinson 1991). In this study, the Fields statistical package (Nychka et al. 2017) was used to implement the TPS algorithm in R software (R Development Core Team 2015). To guide the mapping of $T_{a}$, the 9-second Digital Elevation Model (DEM) was used (Hutchinson et al. 2008). This was reprojected to Geocentric Datum of Australia 94, Geoscience Australia Lambert projection; and resampled to a spatial resolution of $286 \mathrm{~m}$ (roughly equivalent to the spatial resolution of original 9-second DEM). The geographical coordinates of the AWS site locations were then spatially intersected with the newly resampled DEM. This operation provided a consistent template to routinely form TPS models using the AWS observations as data points to the algorithm (on a 30-minute basis). Thus, $T_{a}$ predictions generated by each TPS model were spatially interpolated using the DEM as the $\mathrm{z}$ variable, along with the coordinate parameters of the inherent cell properties of the DEM acting as the latitude (x) and longitude (y) variables. This allowed the spline smoothing parameter to be applied continuously across the geographic feature space of the DEM, resulting in a final mapped prediction; saved as GeoTIFF rasters.

Peer) reviewing PDF | (2020:07:50683:1:1:NEW 13 Sep 2020) 


\section{Evaluating TPS interpolation}

155 The performance of the TPS algorithm was evaluated in the period from 1 March 2019 to 29

156 February 2020. A leave-one-out cross-validation procedure was employed for each AWS site, 157 similar to the method employed in Webb et al. 2020. Specifically, the training dataset was split 158 into $i$ parts such that $i$ is equal to the number of AWS sites, i.e. 534. For each AWS in $i$, the $i^{\text {th }}$ 159 AWS site was kept for validation (i.e. using actual recordings from the evaluation period), while 160 the remaining dataset, comprising of the remaining BoM recordings was used for TPS modelling 161 to predict $\mathrm{T}_{\mathrm{a}}$ at the $i^{\text {th }}$ AWS site. This was performed for each 30-minute interval (h) in the 162 evaluation period to produce a set of modelled TPS estimates versus actual AWS recordings at 163 each site. This equated to 17,567 modelled TPS predictions where observed $\mathrm{T}_{\mathrm{a}}$ - recorded from

164

165

166

167

168

169

170

171

172

173

174

175

176

177

178

179

180

181

182

183

184

185

186

187

188

189

190

191

192 each corresponding AWS site - could then be compared. Validation metrics used to assess the modelling accuracy against the $T_{a}$ recordings, as per Webb et al. 2020, included the mean absolute error (MAE), root-mean-square error (RMSE), coefficient of determination $\left(R^{2}\right)$ and the concordance coefficient. The concordance coefficient $\left(P_{c}\right)$ was used to assess agreement between TPS predictions $x$; and actual recordings $y$; that fall on the $45^{\circ}$ line through the origin, as defined by Lin (1989):

$$
p_{c}=\frac{2 p \sigma_{x} \sigma_{y}}{\sigma_{x}^{2}+\sigma_{y}^{2}+\left(\mu_{x}-\mu_{x}\right)^{2}}
$$

where for $\mu_{x}$ and $\mu_{x}$ represent the means for $x$ and $y$, respectively, $\sigma_{x}^{2}$ and $\sigma_{y}^{2}$ represent the corresponding variances, and $p$ is the correlation coefficient between $x$ and $y$. A concordance rating close to one indicates strong agreement between predicted and actual $T_{a}$ pairings that fall on the $45^{\circ}$ line through the origin.

\section{Application to real-time monitoring of $\mathbf{T}_{\mathbf{a}}$}

The proposed methodology, as advocated by Webb et al. 2020, was adopted in this study for operational real-time monitoring of $\mathrm{T}_{\mathrm{a}}$ across continental Australia. However, since the formation of BoM grids and calibration equations were not required in this study, the methodology was retrofitted to consist of two major components. Firstly, the import of 'live' $\mathrm{T}_{\mathrm{a}}$ data via the internet from the BoM website, and secondly, the mapping of the observations using TPS interpolation. This was trialled over a 21-day period from 1 June 2020 to 21 June 2020, using real-time BoM observations to drive the system which was fully automated using software R (R Development Core Team 2015). Because new BoM observations are typically available every 30-minutes, individual AWS site observations were downloaded at this frequency from the BoM observations portal as comma delimited text files (e.g. http://www.bom.gov.au/fwo/IDT60801/IDT60801.<stationIDnumber >.axf). Thus, the mapping system was programmed to query and import recordings every 30 -minutes (bi-hourly) that corresponded to the nearest half-hour at 0 - and 30 minutes (past the hour). Because of telemetry and associated processing delays (observation updates varied from station to station), the system was programmed to make queries at 5, 10, 15, 20, 25 and 30 minutes within their 30-minute 


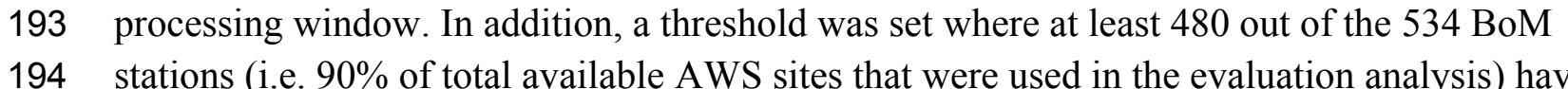

194

195

196

197

198

199

200

201

202

203

204

205

206

207

208

209

210

211

212

213

214

215

216

217

218

219

220

221

222

223

224

225

226

227

228

229

230

231

232 available observations before the mapping was allowed to commence in their respective processing window. This served to limit the number of missing observations that could otherwise produce significant inaccuracies in the subsequent mapped product. However, if this threshold was not met during the allocated query times, the mapping was still permitted to commence at the 30-minute mark regardless of the number of observations available (this was subsequently recorded). To provide context of the proposed system, the same procedure by Webb et al. (2020) found that most observations tended to be imported at the 15-minute mark (from the nearest observation hour) with corresponding TPS maps completed thereafter at the 17-minute mark. The rationale for this study assumes a similar time frame, albeit at bi-hourly intervals, where observations are imported every 30-minutes (with an import time lag of $\sim 15$-minues from the nearest half-hour), followed by $\mathrm{T}_{\mathrm{a}}$ mapping thereafter. Note that all AWS recording times in this study were standardised to Australian Eastern Standard Time (AEST).

To interpolate the TPS predictions, the processing schema described in Webb et al. 2020 was used. This consisted the Raster package (Hijmans \& van Etten 2012) in combination with the Fields statistical package (Nychka et al. 2017) using software R (R Development Core Team 2015), to map and subsequently visualize the predictions in a continuous manner across Australia. To improve processing speed, the clusterR function within the Raster package was parameterised to host the TPS algorithm, thereby enabling mapping to occur using multi-core processors. In this manner, the mapping system was hosted on a high-end cloud computing Linux platform (Ubuntu 18.04 LTS (Bionic)) constituting 16 virtual CPU cores and 64GB RAM; made available courtesy of the Australian National eResearch Collaboration Tools and Resources project (NeCTAR). Spatial outputs were saved as individual GeoTIFF raster format at a grid cell resolution of $286 \mathrm{~m}$, i.e. equivalent to the spatial resolution of the resampled DEM.

\section{Results}

\section{Assessment of the TPS interpolation procedure}

Each of the AWS sites underwent the leave-one-out cross-validation analysis to assess TPS prediction accuracy for $\mathrm{T}_{\mathrm{a}}$ in the evaluation period: 1 March 2019 to 29 February 2020. This analysis revealed broad similarities across the seasons with MAE values ranging from $1.2^{\circ} \mathrm{C}$ (autumn and summer) to $1.3^{\circ} \mathrm{C}$ (winter and spring), and similarly RMSE ranging from $1.6^{\circ} \mathrm{C}$ to $1.7^{\circ} \mathrm{C}$ (Table 1 ). The $R^{2}$ and $P_{c}$ values were above 0.8 indicating that the TPS predictions were strongly correlated to the validation data in addition to being highly associated with the $45^{\circ}$ line through the origin (Lin 1989). This assessment also implied that predictions were relatively consistent across the evaluation period and did not vary substantially on a seasonal basis.

Moreover, it implied that the TPS interpolation was more suited to predicting $\mathrm{T}_{\mathrm{a}}$ in autumn which tended to exhibit superior statistics across all validation measures when compared to the other 
233 seasons. This was particularly evident regarding $R^{2}$ and $P_{c}$, which registered the highest values of 2340.91 and 0.94 , respectively. However, TPS predictions tended to be least accurate in spring and 235 winter which had MAE and RMSE values greater by $0.1^{\circ} \mathrm{C}$, when compared to the 236 corresponding MAE and RMSE values in autumn. Interestingly, although spring exhibited 237 comparatively inferior MAE and RMSE values, the $R^{2}$ statistics were similar, both registering 238 0.91. This suggests that while errors were comparatively larger in spring, they were still very 239 highly correlated to the validation data. However, it should be noted that the coefficient of 240 determination may have been unrealistically overestimated for spring since the seasonal data signal was not removed prior to analysis, as advocated in Jeffrey et al. (2001).

245

246

247

248

249

250

251

252

253

254

255

256

257

258

259

260

261

262

263

264

265

266

267

268

269

270

271

272

When looking at the histogram distribution of the MAE and RMSE it was apparent that spring and winter had a notable proportion of AWS sites that exhibited values above $2^{\circ} \mathrm{C}$ (Fig. 3). This contributed to the inflated error values shown in Table 1. Specifically, spring and winter both had a total of 42 and 46 AWS sites that registered MAE above $2^{\circ} \mathrm{C}$, compared to 22 and 16 AWS sites for summer and autumn, respectively. Similarly, spring and winter also had a large proportion of RMSE values above $2^{\circ} \mathrm{C}$ with 147 and $134 \mathrm{AWS}$ sites, respectively, compared to 95 and 91 AWS sites for summer and autumn, respectively. In regard to $R^{2}$ and $P_{c}$, winter had a greater proportion of AWS sites that exhibited moderate to weak correlation $(\leq 0.7)$ with 45 and 32 sites, respectively; compared to 37 and 17 in summer, 11 and 10 in spring, and 13 and 8 in autumn. The high proportion of low $R^{2}$ values in winter contributed to the lowest $R^{2}$ value of 0.86 , compared to $0.89,0.91$ and 0.91 for summer, autumn and spring, respectively (Table 1).

When viewing the errors spatially, it was clear that most of the larger interpolation errors transpired in regions where there was a lack of neighbouring AWS sites (Fig. 4). Specifically, the central and western interior parts of Australia tended to exhibit MAE and RMSE values above $2^{\circ} \mathrm{C}$, compared to the eastern half where temperatures were consistently predicted within $2^{\circ} \mathrm{C}$ of the actual $\mathrm{T}_{\mathrm{a}}$. Of note was the predominately high errors encountered for the coastal areas of Western Australia (between Geraldton and Port Hedland) during summer and spring where the MAE and RMSE prediction errors regularly exceeded $2.5^{\circ} \mathrm{C}$. For example, the Learmonth Airport AWS site (Fig. 2) in spring had MAE and RMSE of $3.4^{\circ} \mathrm{C}$ and $4.3^{\circ} \mathrm{C}$, respectively, in addition to summer with corresponding MAE and RMSE of $3.2^{\circ} \mathrm{C}$ and $4.2^{\circ} \mathrm{C}$, respectively. Outside of this cluster, there were also high MAE and RMSE values for individual AWS sites located at Pirlangimpi Airport (Tiwi Islands, Northern Territory) in spring with $3.6^{\circ} \mathrm{C}$ and $4.3^{\circ} \mathrm{C}$, respectively; Forrest in Western Australia during summer with corresponding MAE and RMSE of $2.9^{\circ} \mathrm{C}$ and $3.8^{\circ} \mathrm{C}$, respectively; and Yampi Sound in the Northern Territory during winter with MAE and RMSE of $3.3^{\circ} \mathrm{C}$ and $4.3^{\circ} \mathrm{C}$, respectively. Furthermore, in winter there was a notable cluster of high MAE values emanating from central Australia through to the coastal fringes of Northern Territory and Western Australia (i.e. Darwin through to Broome) with MAE and RMSE consistently above $2^{\circ} \mathrm{C}$.

Peer) reviewing PDF | (2020:07:50683:1:1:NEW 13 Sep 2020) 
273 In terms of the $R^{2}$ and $P_{c}$, low values tended to emanate along the coastal regions, particularly for 274 Western Australia, Northern Territory and North Queensland coastal regions and neighbouring 275 islands (Fig. 4). For example, the lowest values were encountered for sites Pirlangimpi Airport, 276 Browse Island and Coconut Island in spring with $R^{2}$ of $0.01,0.1$ and 0.1 , respectively, and $P_{c}$ of $2770.09,0.25$ and 0.23 , respectively. Summer also encountered low $R^{2}$ of $0.05,0.05$ and 0.31 , 278 respectively, with corresponding $P_{c}$ of $0.18,0.2$ and 0.52 . The same sites in winter also had the 279 lowest $R^{2}$ of $0.41,0.01$ and 0.14 , respectively, along with corresponding $P_{c}$ of $0.48,0.08$ and $280 \quad 0.27$.

281

282

283

284

285

286

287

288

289

290

291

292

293

294

295

296

297

298

299

300

301

302

303

304

305

306

307

308

309

310

311

312

When observing MAE (Fig. 5) and RMSE (Fig. 6) over a 24-hour period, it was clear that the high values encountered for the coastal areas of Western Australia in summer and spring tended to occur during afternoons. Specifically, these had MAE and RMSE ranging between $4-6^{\circ} \mathrm{C}$ for times $3 \mathrm{pm}$ to $6 \mathrm{pm}$, i.e. $1 \mathrm{pm}$ to $4 \mathrm{pm}$, Australian Western Standard Time (AWST). Of note was the Learmonth Airport AWS site registering MAE of $6.9^{\circ} \mathrm{C}$ and RMSE of $7.6^{\circ} \mathrm{C}$, peaking at 5 pm (3 pm, AWST) in summer (Fig. 7). Similarly, very high error values were encountered for the south-eastern area of Western Australia in spring, notably for the Forrest AWS site at $6 \mathrm{pm}$, which registered $6.1^{\circ} \mathrm{C}$ and $6.3^{\circ} \mathrm{C}$ for MAE and RMSE, respectively. This was in addition to $5.3^{\circ} \mathrm{C}$ and $7^{\circ} \mathrm{C}$, respectively, for the same site in summer, along with the Ceduna AWS site (South Australia) at $6 \mathrm{pm}$, registering high MAE and RMSE values of $5.4^{\circ} \mathrm{C}$ and $6^{\circ} \mathrm{C}$, respectively. During winter the trend for high MAE and RMSE emanating from central Australia and the coastal fringes of Northern Territory and Western Australia tended to occur during early mornings from $3 \mathrm{am}$ to $9 \mathrm{am}(1 \mathrm{am}$ to $7 \mathrm{am}, \mathrm{AWST})$, with MAE and RMSE ranging $3-5^{\circ} \mathrm{C}$. The AWS sites with the greatest error in these parts were Adele Island and Yampi Sound which both registered a MAE of $6.4^{\circ} \mathrm{C}$ and RMSE of $6.4^{\circ} \mathrm{C}$ and $6.7^{\circ} \mathrm{C}$, respectively (Fig. $5 \& 6$ ). Both sites are located in the northern coastal region of Western Australia (NB: the locations of all aforementioned AWS sites are depicted in Fig. 2).

Regarding $R^{2}$ and $P_{c}$, it was revealed that low values $<0.5$ were mostly evident during late nights and early mornings, particularly during winter and summer (Fig. $8 \& 9$ ). This tended to be prevalent throughout the central western interior and the coastal fringes of Western Australia, Northern Territory and North Queensland. Specifically, $R^{2}$ and $P_{c}<0.5$ tended to occur from midnight through to $6 \mathrm{am}$, suggesting that the TPS predictions were not highly correlated with the validation data during these times. This occurred despite the RMSE and MAE registering values below $2^{\circ} \mathrm{C}$ for some sites. For example, the AWS site at Browse Island during summer at 12 am registered $R^{2}$ and $P_{c}$ values of 0.04 and 0.2 , respectively, while MAE and RMSE was $0.9^{\circ} \mathrm{C}$ and $1.1^{\circ} \mathrm{C}$, respectively (Fig. 7). This was also encountered for the Coconut Island AWS during winter mornings, e.g. at 9 am where the $R^{2}$ and $P_{c}$ values registered 0.0 and 0.1 , respectively, while the MAE and RMSE was $1.4^{\circ} \mathrm{C}$ and $1.7^{\circ} \mathrm{C}$, respectively. This suggested that while predictions were reasonably accurate, there was little to no correlation with the validation data.

Peer) reviewing PDF | (2020:07:50683:1:1:NEW 13 Sep 2020) 
315 The TPS methodology was applied to mapping $T_{a}$ in real-time at 30-minute intervals over a 21316 day period from 1 June 2020 to 21 June 2020. This exercise resulted in 1007 maps being 317 produced which aligned to the total number of 30 -minute processing intervals in the trial period; 318 confirming all possible maps were successfully processed. On analysing the map completion 319 times, the majority of the maps were completed at 28-minutes (Fig. 10). Specifically, 410 and

320

321

322

323

324

325

326

327

328

329

330

331

332

333

334

335

336

337

338

339

340

341

342

343

344

345

346

347

348

349

350

351

352

414 maps were produced for their respective 0 - and 30-minute processing intervals. This corresponded directly to the AWS import times (Fig. 11), with the same proportion of AWS observations reaching the 480-observation threshold import limit at the 15-minute mark; thereby permitting $\mathrm{T}_{\mathrm{a}}$ mapping to commence. Thus, import times that occurred at 15-minutes, equated to resulting maps being completed at 28-minutes from the AWS observation time. From this, it can be deduced that on all occasions the map processing time was 13-minutes, regardless of the interval being processed. It should be noted that on 35 occasions the 480 -observation threshold limit was not reached, resulting in maps - that did not meet this criterion - being produced at the 30 -minute mark. This equated to 14 and 21 maps produced at the 0 - and 30-minute processing intervals, respectively.

\section{Discussion}

\section{Appraisal of the TPS interpolation procedure}

On the whole, the TPS interpolation method was a reliable predictor of $\mathrm{T}_{\mathrm{a}}$ across Australia with an RMSE of $1.65^{\circ} \mathrm{C}$, i.e. when averaged across the seasons (Table 1). When compared to previous studies, this error was similar to Jeffrey et al. (2001) with RMSE of $1.5^{\circ} \mathrm{C}$ and $1.9^{\circ} \mathrm{C}$ for daily maximum and minimum temperatures, respectively; and Jones et al. (2009) with corresponding RMSE of $1.2^{\circ} \mathrm{C}$ and $1.7^{\circ} \mathrm{C}$. On a seasonal basis the TPS predictions tended to be least accurate in spring and winter which had MAE and RMSE values larger by $0.1^{\circ} \mathrm{C}$ compared to the same measures in autumn. When viewing these errors spatially, it was clear that the majority of the larger interpolation errors transpired in the central and western interior parts of Australia. This is unsurprising given the station density in these parts are relatively sparse in addition to large temperature variances which tend to produce inflated errors (Jeffrey et al. 2001; Jones \& Trewin 2000). Of note was the predominately high errors encountered for the coastal areas of Western Australia (between Geraldton and Port Hedland) during summer and spring afternoons where prediction errors were regularly above $2.5^{\circ} \mathrm{C}$. This was in addition to high MAE values for individual AWS sites located at Forrest in Western Australia and Ceduna in South Australia. Collectively, these regions tend to experience very strong temperature gradients, particularly concerning maximum temperatures, since their proximity between the coast and inland deserts result in local climate regimes being invariably affected by the relatively cool ocean to the west and hot desert interior to the east (Jones et al. 2009). These are increasingly difficult to model with a sparse network of observation sites since these errors tended to be amplified during mid to late afternoons in late spring and summer when the temperature

Peer] reviewing PDF | (2020:07:50683:1:1:NEW 13 Sep 2020) 
353

354

355

356

357

358

359

360

361

362

363

364

365

366

367

368

369

370

371

372

373

374

375

376

377

378

379

380

381

382

383

384

385

386

387

388

389

390

391

392

gradients were at their peak. Also, temperatures in these areas vary considerably over short periods leading to a tendency for larger errors (Jones \& Trewin 2000).

Concerning winter, the trend for high MAE and RMSE in central Australia and coastal fringes of Northern Territory and Western Australia tended to occur during early mornings from 3 am to 9 am (1 am to 7 am, AWST). As acknowledged previously, the accuracy of the mapping was limited in these regions due to an insufficient network of AWS sites. Also, AWS sites in the coastal fringes tend to have tight climate gradients as a result of local maritime effects (Jones et al. 2009). This possibly contributed to the low $R^{2}$ and $P_{c}$ values encountered in Fig. 4, 8 \& 9 despite some AWS sites exhibiting relatively small MAE and RMSE values, e.g. Browse Island and Coconut Island AWS sites (Fig. 7). Thus, the predictions tended to be highly variable over a narrower prediction range due to the tighter temperature gradient in these climates. Combined with a sparse network of AWS sites, the TPS method was unable to account for this on a subhourly timescale. Moreover, the spread of AWS sites in remote coastal locations - e.g. Adele Island, Yampi Sound and Pirlangimpi Airport AWS sites - tend to have considerably larger errors as a result of unique and often complex microclimates, thereby compounding the variability (Jones et al. 2009). It should also be noted that the larger errors for the central interior parts of Australia may also be due to the weaker link between altitude and temperature - for which the TPS algorithm is reliant (Hutchinson 1991). This is because minimum temperatures have a highly variable and complex relationship with topography for which elevation and its association with lapse rates are only one part (Rolland 2003; Trewin 2005). Considering minimum temperatures tend to transpire during early mornings - as encountered for AWS sites in winter (Fig. 5 \& 6) - a multivariate approach to modelling might be more appropriate along with a denser network of AWS sites. This approach was conducted by Webb et al. (2020), and showed errors improved during winter when using regression tree interpolation (along with multiple terrain and satellite covariate datasets). However, the substantially longer processing times may not be appropriate for real-time application, negating its ability to produce outputs in a timely manner as required for this study. Similar experiments contrasting TPS, ordinary kriging and inverse distance weighting interpolation found that TPS was more accurate and required few guiding covariates (Jarvis \& Stuart 2001b). This justified the selection of the TPS method in the current study, even though kriging can be an equally effective method (Hutchinson 1991). However, kriging requires considerable computational overhead (Jarvis \& Stuart 2001b) and therefore, in the context of this study, not ideal for real-time application.

It should be commented that the cross-validation analysis adopted in this study would likely overestimate the error since predictions were made at locations that have actual data observations. This would be less of a concern for regions where the number of observation points is numerous, such as for the majority of land areas in south-east Australia - which tended to have more accurate $T_{a}$ predictions compared to the western interior. Nevertheless, this exemplifies that the sparse network of AWS sites in central and western coastal areas of Australia was a notable 
393

394

395

396

397

398

399

400

401

402

403

404

405

406

407

408

409

410

411

412

413

414

415

416

417

418

419

420

421

422

423

424

425

426

427

428

429

430

431

432

factor contributing to larger interpolation errors. It should be further commented that while the cross-validation analysis was valid using a static dataset, in reality and as exemplified during real-time application, interpolation could only commence when the predefined threshold of 480 AWS observations was met. Thus, on most occasions' predictions were based on the minimum allowable number of AWS sites and therefore prone to produce less accurate predictions compared to using an entire dataset. To evaluate this scenario, a K-fold cross validation was implemented (Hastie et al. 2009). Specifically, the training dataset - represented by AWS observations in each 30-minute interval (h) within the evaluation period - was split into K equal parts using random sampling. Where the Kth part was kept for validation and the remaining K-1 part were combined for TPS modelling in each fold. In this manner, the predictions produced by the modelling were assessed against the held back validation subset and was repeated $\mathrm{K}$ times, such that each $\mathrm{K}$ validation subset was used once to assess the $\mathrm{K}-1$ model. In this study, $\mathrm{K}=10$ was specified, representing $90 \%$ of the dataset for TPS modelling and $10 \%$ for validation in each fold, i.e. equivalent to 480 and 54 AWS sites, respectively.

The result of the K-fold analysis (Table 2 ) revealed broad similarities with Table 1. For example, the MAE of $1.2^{\circ} \mathrm{C}, 1.2^{\circ} \mathrm{C}, 1.3^{\circ} \mathrm{C}$ and $1.3^{\circ} \mathrm{C}$, respectively for summer, autumn, winter and spring, and corresponding RMSE of $1.7^{\circ} \mathrm{C}, 1.6^{\circ} \mathrm{C}, 1.7^{\circ} \mathrm{C}$ and $1.8^{\circ} \mathrm{C}$, respectively, deviated by no more than $0.1^{\circ} \mathrm{C}$ when compared to the equivalent measures in Table 1 . This indicated that overall the prediction accuracy did not deteriorate greatly when interpolation was based on the minimum allowable number of AWS sites. It also justified that the $480 \mathrm{AWS}$ threshold adopted in this study was an acceptable limit for the real-time application.

\section{Appraisal of mapping $T_{a}$ in near real-time and application to digital mapping}

The TPS interpolation applied in real-time was capable of producing sub-hourly $\mathrm{T}_{\mathrm{a}}$ maps typically within 28-minutes of the observation being recorded by the available AWS sites (Fig. 10). Specifically, import times were generally reached for the predefined threshold of 480 observations at the 15-minute mark (Fig. 11) which was followed by a 13-minute processing lag. In this regard, maps were consistently available within their 30-minute processing window and had a high degree of temporal reliability - with all possible maps produced in the 21-day trial period. The resulting maps were presented on a digital web mapping platform to allow real-time access and interrogation ability of each output. An example of this application can be accessed at URL http://austemperature.live/ (Fig. 12). A GeoServer backend was used to host current outputs to allow geospatial representation and sharing of outputs via a Wep Map Service (Open Source Geospatial Foundation 2019). The maps can be spatially queried to reveal temperatures for the current hour and for the previous 3-hrs (at 30-minute intervals). This is enabled via web application packages shiny and leaflet (Chang et al. 2019; Cheng et al. 2019) within the R programming environment (R Development Core Team 2015). In this fashion, maps can be spatially interrogated via an on-the-fly 'data drilling' for any geographical location in Australia (via mouse click). A facility to view the cross-validation statistics of each map output is also 
433 provided as well as the ability to download each newly created map for use in GIS applications.

434 A potential new feature is to provide an error map for each subsequent map produced (similar to 435 Fig. 5 \& 6). This would provide an approximate error measure for regions with limited AWS

436 sites which tended to be high, as encountered in this study. Note that rainfall mapping outputs are 437 also presented in the application, although this should be used with caution due to the 438 preliminary nature of this work.

439

\section{Conclusions}

441 The methods described in this study were successful for operational real-time spatial mapping of $442 \mathrm{~T}_{\mathrm{a}}$ at high spatiotemporal across Australia. The TPS interpolation method was best suited for 443 mapping $T_{a}$ during autumn and was comparatively less accurate during winter and spring. In 444 particular, areas, where there was a lack of AWS sites, tended to underperform. These areas 445 included the central and western interior regions of Australia, as well for the north-west coastal 446 areas of Western Australia and parts of the Northern Territory coastline. On a temporal basis, the 447 errors were amplified during the afternoons, particularly around the coastal regions of Western 448 Australia, during spring and summer. In winter, errors tended to be higher in central Australia 449 and the coastal fringes of Northern Territory and Western Australia, from 3 am to 9 am. In terms 450 of applying the TPS method to real-time operational mapping, the mapping system was able to 451 regularly provide spatial outputs within 28-minutes of AWS site observations being recorded. In 452 addition, it also had a high degree of temporal reliability with all maps produced in the 21-day 453 trial period. Outputs were sequentially displayed on purpose-built web mapping application to 454 exemplify real-time application of the outputs. In this regard, the methodology employed in this 455 study would be highly suited for similar applications requiring real-time processing and delivery 456 of climate data at high spatiotemporal resolutions across a large landmass, suitably

457 complimented with a relatively dense network of observation sites.

458

459

460

461

462

463

\section{Acknowledgements}

This research was supported by Tasmanian Partnership for Advanced Computing and by use of the Nectar Research Cloud. The Nectar Research Cloud is a collaborative Australian research platform supported by the National Collaborative Research Infrastructure Strategy (NCRIS). 


\section{References}

465 Aadhar S, and Mishra V. 2017. High-resolution near real-time drought monitoring in South Asia.

466

467

468

469

470

471

472

473

474

475

476

477

478

479

480

481

482

483

484

485

486

487

488

489

490

491

492

493

494

495

496

497

498

499

500

501

502

503

504

505

506

507

508

509

510

511

512 Scientific Data 4:170145. 10.1038/sdata.2017.145

Bollmeyer C, Keller JD, Ohlwein C, Wahl S, Crewell S, Friederichs P, Hense A, Keune J, Kneifel S, Pscheidt I, Redl S, and Steinke S. 2015. Towards a high-resolution regional reanalysis for the European CORDEX domain. Quarterly Journal of the Royal Meteorological Society 141:1-15. 10.1002/qj.2486

Bureau of Meteorology. 2018. Bureau of Meteorology website. (Australian Government). Available at http://www.bom.gov.au/climate/cdo/about/airtemp-measure.shtml (accessed 11 August.

Chang W, Cheng J, Allaire J, Xie Y, and McPherson J. 2019. shiny: Web Application Framework for R. R package version 1.4.0. https://CRAN.R-project.org/package=shiny.

Cheng J, Karambelkar B, and Xie Y. 2019. leaflet: Create Interactive Web Maps with the JavaScript 'Leaflet' Library. R package version 2.0.3. https://CRAN.Rproject.org/package=leaflet.

Hastie T, Tibshirani R, and Friedman J. 2009. The elements of statistical learning (2nd edition): Springer-verlag, New York.

Hijmans RJ, and van Etten J. 2012. raster: Geographic analysis and modeling with raster data. $\mathrm{R}$ package version 2.0-12. http://CRAN.R-project.org/package=raster.

Hutchinson M. 1991. The application of thin plate smoothing splines to continent-wide data assimilation. In: Jasper J, editor. Data Assimilation Systems. Melbourne, Vic, Australia: Bureau of Meteorology. p 104-113.

Hutchinson MF, Stein JL, Stein JA, Anderson H, and Tickle PK. 2008. GEODATA 9 second DEM and D8: Digital Elevation Model Version 3 and Flow Direction Grid. Record DEM9S.v3. Geoscience Australia, Canberra.

Jarvis $\mathrm{CH}$, and Stuart N. 2001a. A comparison among strategies for interpolating maximum and minimum daily air temperatures. Part I: The selection of "guiding" topographic and land cover variables. Journal of Applied Meteorology 40:1060-1074.

Jarvis $\mathrm{CH}$, and Stuart N. 2001b. A comparison among strategies for interpolating maximum and minimum daily air temperatures. Part II: The interaction between number of guiding variables and the type of interpolation method. Journal of Applied Meteorology 40:10751084.

Jeffrey SJ, Carter JO, Moodie KB, and Beswick AR. 2001. Using spatial interpolation to construct a comprehensive archive of Australian climate data. Environmental Modelling \& Software 16:309-330. https://doi.org/10.1016/S1364-8152(01)00008-1

Jones DA, and Trewin BC. 2000. On the relationships between the EI Niño-Southern Oscillation and Australian land surface temperature. International journal of climatology 20:697-719. 10.1002/1097-0088(20000615)20:7<697::aid-joc499>3.0.co;2-a

Jones DA, Wang W, and Fawcett R. 2009. High-quality spatial climate data-sets for Australia. Australian Meteorological and Oceanographic Journal 58:233.

Lazzarini M, Marpu PR, Eissa Y, and Ghedira H. 2014. Toward a Near Real-Time Product of Air Temperature Maps from Satellite Data and In Situ Measurements in Arid Environments. IEEE Journal of Selected Topics in Applied Earth Observations and Remote Sensing 7:3093-3104. 10.1109/JSTARS.2014.2320762

Li Z, Guo J, Ding A, Liao H, Liu J, Sun Y, Wang T, Xue H, Zhang H, and Zhu B. 2017. Aerosol and boundary-layer interactions and impact on air quality. National Science Review 4:810-833. 10.1093/nsr/nwx117

Lin LIK. 1989. A Concordance Correlation Coefficient to Evaluate Reproducibility. Biometrics 45:255-268. 10.2307/2532051 
513

514

515

516

517

518

519

520

521

522

523

524

525

526

527

528

529

530

531

532

533

534

535

536

537

538

539

540

541

542

543

544

545

546

547

548

549

550

551

552

553

554

555

556

557

558

559

560

561

562

563

Liu L, Guo J, Chen W, Wu R, Wang L, Gong H, Xue W, and Li J. 2018a. Large-Scale Pattern of the Diurnal Temperature Range Changes over East Asia and Australia in Boreal Winter: A Perspective of Atmospheric Circulation. Journal of Climate 31:2715-2728. 10.1175/jclid-17-0608.1

Liu S, Su H, Tian J, and Wang W. 2018b. An analysis of spatial representativeness of air temperature monitoring stations. Theoretical and Applied Climatology 132:857-865. 10.1007/s00704-017-2133-6

Mao KB, Ma Y, Tan XL, Shen XY, Liu G, Li ZL, Chen JM, and Xia L. 2017. Global surface temperature change analysis based on MODIS data in recent twelve years. Advances in Space Research 59:503-512. https://doi.org/10.1016/j.asr.2016.11.007

Mitchell JFB, Davis RA, Ingram WJ, and Senior CA. 1995. On Surface Temperature, Greenhouse Gases, and Aerosols: Models and Observations. Journal of Climate 8:23642386. 10.1175/1520-0442(1995)008<2364:ostgga>2.0.co;2

Nychka D, Furrer R, Paige J, and Sain S. 2017. fields: Tools for spatial data. R package version 10.3. https://github.com/NCAR/Fields.

Open Source Geospatial Foundation. 2019. Geoserver: an open source software server for sharing and editing geospatial data. GeoServer 2.17.1. http://geoserver.org/release/stable/.

R Development Core Team. 2015. R: A language and environment for statistical computing. $R$ Foundation for Statistical Computing. Vienna, Austria.

Rolland C. 2003. Spatial and Seasonal Variations of Air Temperature Lapse Rates in Alpine Regions. Journal of Climate 16:1032-1046. 10.1175/15200442(2003)016<1032:sasvoa>2.0.co;2

Sobrino J, Julien Y, and García-Monteiro S. 2020. Surface Temperature of the Planet Earth from Satellite Data. Remote Sensing 12:218. 10.3390/rs12020218

Su CH, Eizenberg N, Steinle P, Jakob D, Fox-Hughes P, White CJ, Rennie S, Franklin C, Dharssi I, and Zhu H. 2019. BARRA v1.0: the Bureau of Meteorology Atmospheric highresolution Regional Reanalysis for Australia. Geosci Model Dev 12:2049-2068. 10.5194/gmd-12-2049-2019

Trewin BC. 2005. A notable frost hollow at Coonabarabran, New South Wales. Australian Meteorological Magazine 54:15-21.

Wang K, Sun J, Cheng G, and Jiang H. 2011. Effect of altitude and latitude on surface air temperature across the Qinghai-Tibet Plateau. Journal of Mountain Science 8:808-816. 10.1007/s11629-011-1090-2

Webb M, Hall A, Kidd D, and Minasny B. 2016. Local-scale spatial modelling for interpolating climatic temperature variables to predict agricultural plant suitability. Theoretical and Applied Climatology 124:1145-1165. 10.1007/s00704-015-1461-7

Webb MA, Kidd D, and Minasny B. 2020. Near real-time mapping of air temperature at high spatiotemporal resolutions in Tasmania, Australia. Theoretical and Applied Climatology 141:1181-1201. 10.1007/s00704-020-03259-4

Williams M, Cornford D, Bastin L, Jones R, and Parker S. 2011. Automatic processing, quality assurance and serving of real-time weather data. Computers \& Geosciences 37:353362. https://doi.org/10.1016/j.cageo.2010.05.010

Xu Y, Knudby A, Shen Y, and Liu Y. 2018. Mapping Monthly Air Temperature in the Tibetan Plateau From MODIS Data Based on Machine Learning Methods. IEEE Journal of Selected Topics in Applied Earth Observations and Remote Sensing 11:345-354. 10.1109/JSTARS.2017.2787191

Xue W, Guo J, Zhang Y, Zhou S, Wang Y, Miao Y, Liu L, Xu H, Li J, Chen D, and Liu H. 2019. Declining diurnal temperature range in the North China Plain related to environmental changes. Climate Dynamics 52:6109-6119. 10.1007/s00382-018-4505-8

Peer) reviewing PDF | (2020:07:50683:1:1:NEW 13 Sep 2020) 
Figure 1

Workflow developed for this study

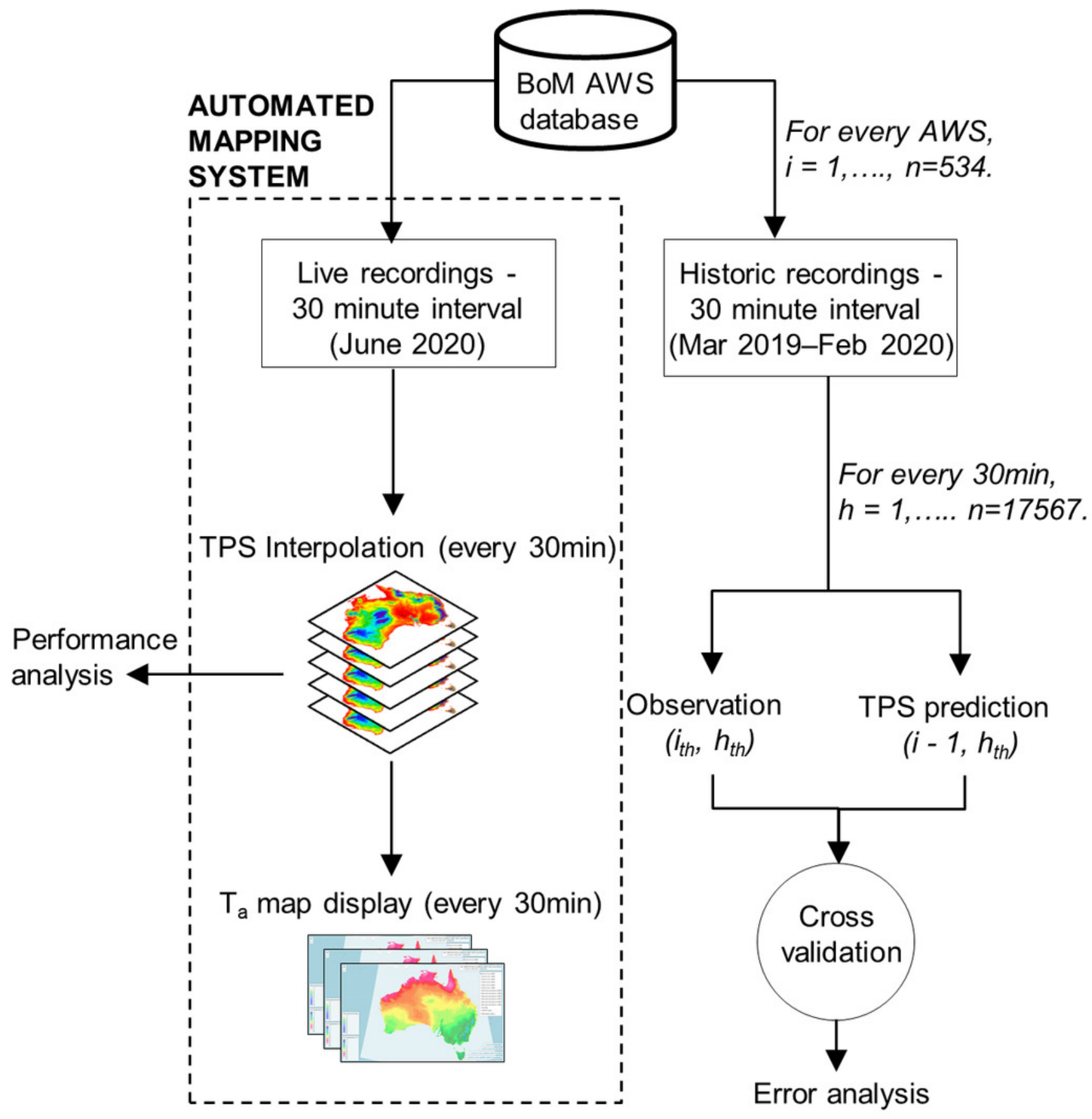


Figure 2

Elevation map of Australia with locations of major towns/cities and Bureau of Meteorology (BoM) automatic weather stations (AWS).

Purple dots illustrate AWS locations. Red dots denote locations of notable AWS sites (refer results section)

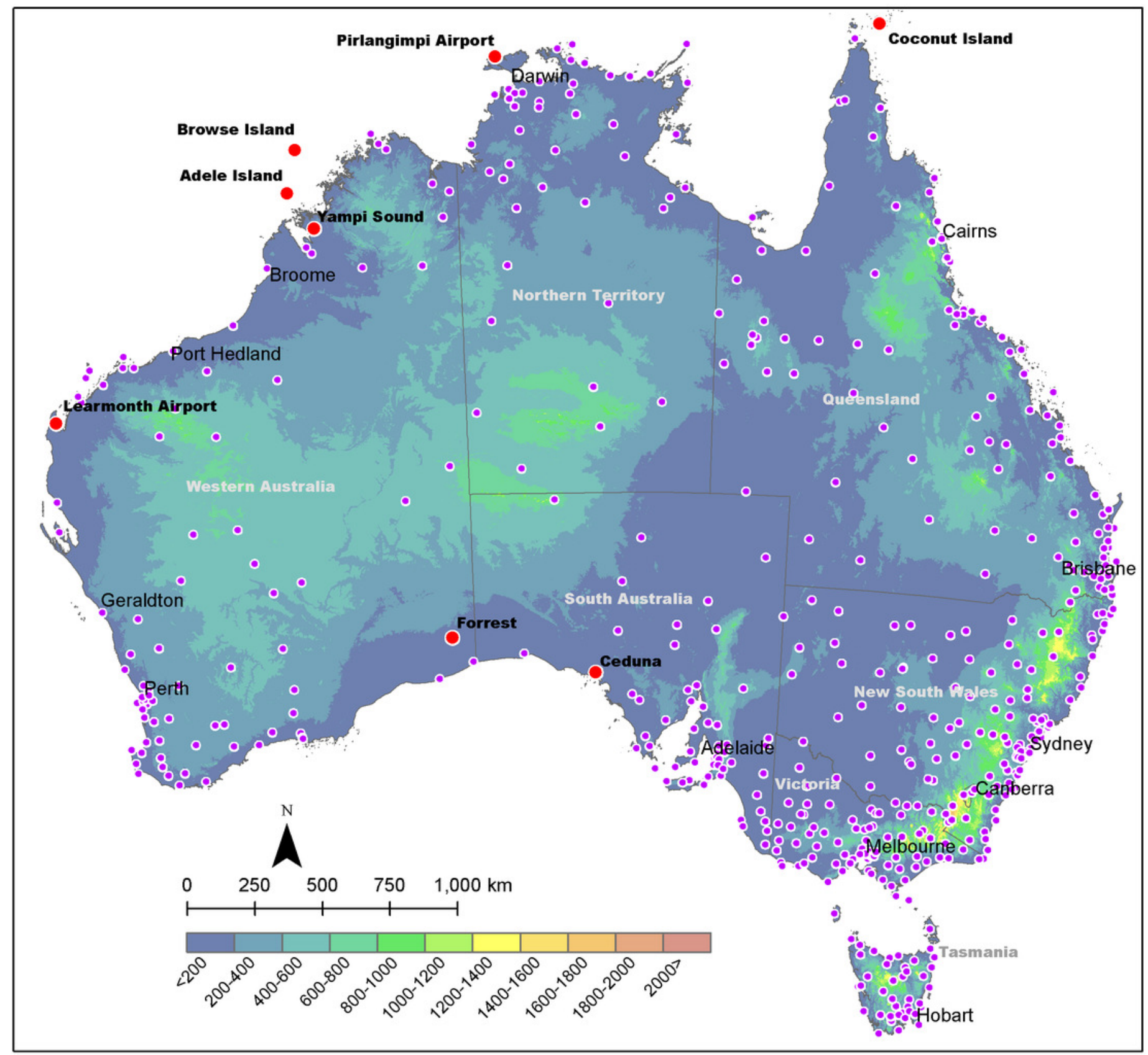


Figure 3

Histogram plots of validation metrics for MAE, RMSE, $R^{2}$ and $P_{c}$ according to each season.

(A) MAE in autumn. (B) MAE in winter. (C) MAE in spring. (D) MAE in summer. (E) RMSE in autumn. (F) RMSE in winter. (G) RMSE in spring. (H) RMSE in summer. (I) $R^{2}$ in autumn. (J) $R^{2}$ in winter. (K) $R^{2}$ in spring. (L) $R^{2}$ in summer. $(M) P_{c}$ in autumn. (N) $P_{c}$ in winter. (O) $P_{c}$ in spring.

(P) $P_{c}$ in summer.

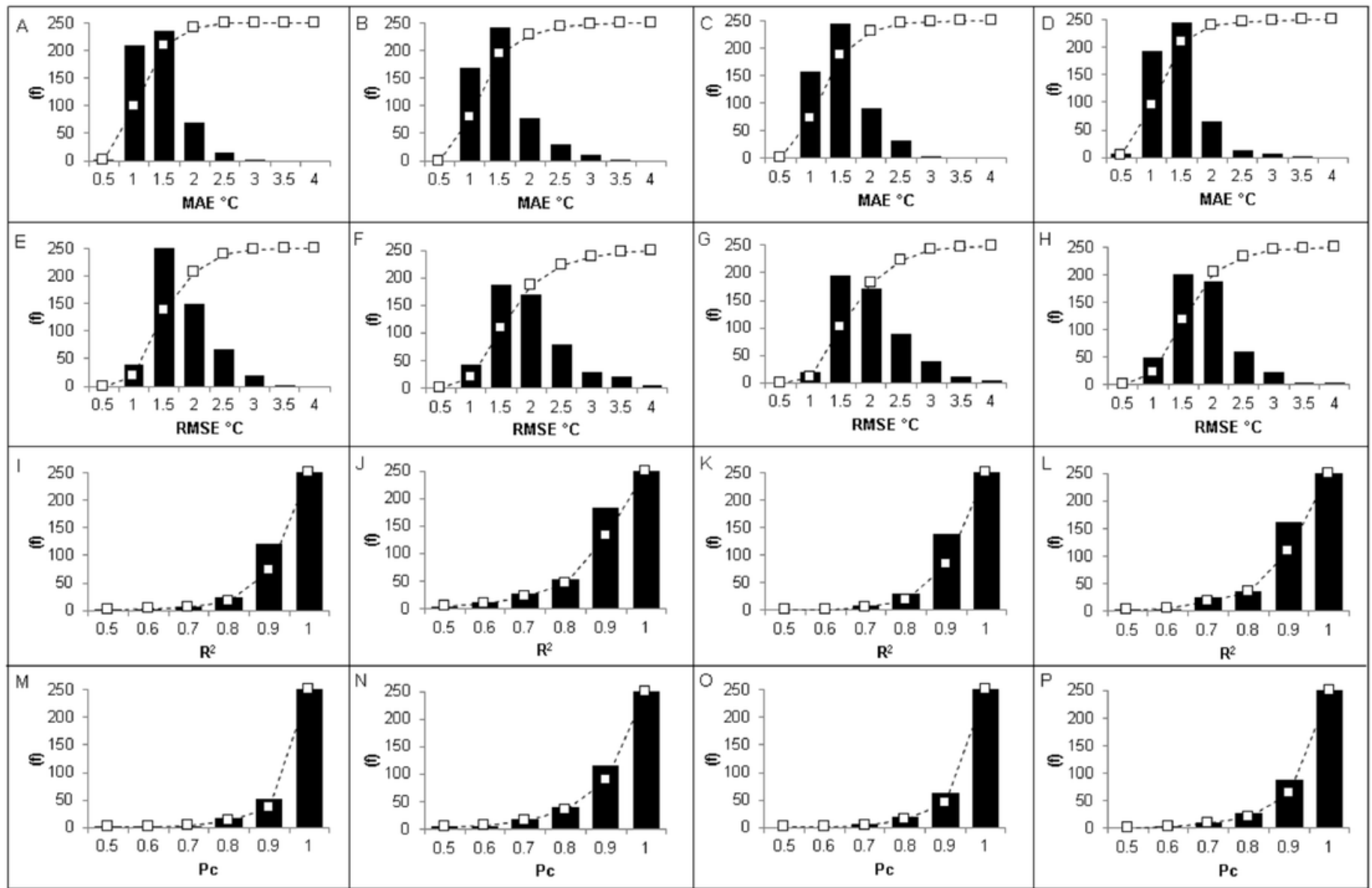




\section{Figure 4}

Interpolated validation metrics (using a two-dimensional smoothing spline) for MAE,

RMSE, $\mathrm{R}^{2}$ and $\mathrm{P}_{\mathrm{c}}$ according to each season.

(A) MAE in autumn. (B) MAE in winter. (C) MAE in spring. (D) MAE in summer. (E) RMSE in autumn. (F) RMSE in winter. (G) RMSE in spring. (H) RMSE in summer. (I) $R^{2}$ in autumn. (J) $R^{2}$ in winter. (K) $R^{2}$ in spring. (L) $R^{2}$ in summer. (M) $P_{c}$ in autumn. (N) $P_{c}$ in winter. (O) $P_{c}$ in spring. (P) $P_{c}$ in summer. Black dots within each panel denote AWS sites where values are above the $95^{\text {th }}$ percentile (labelled with their corresponding value).

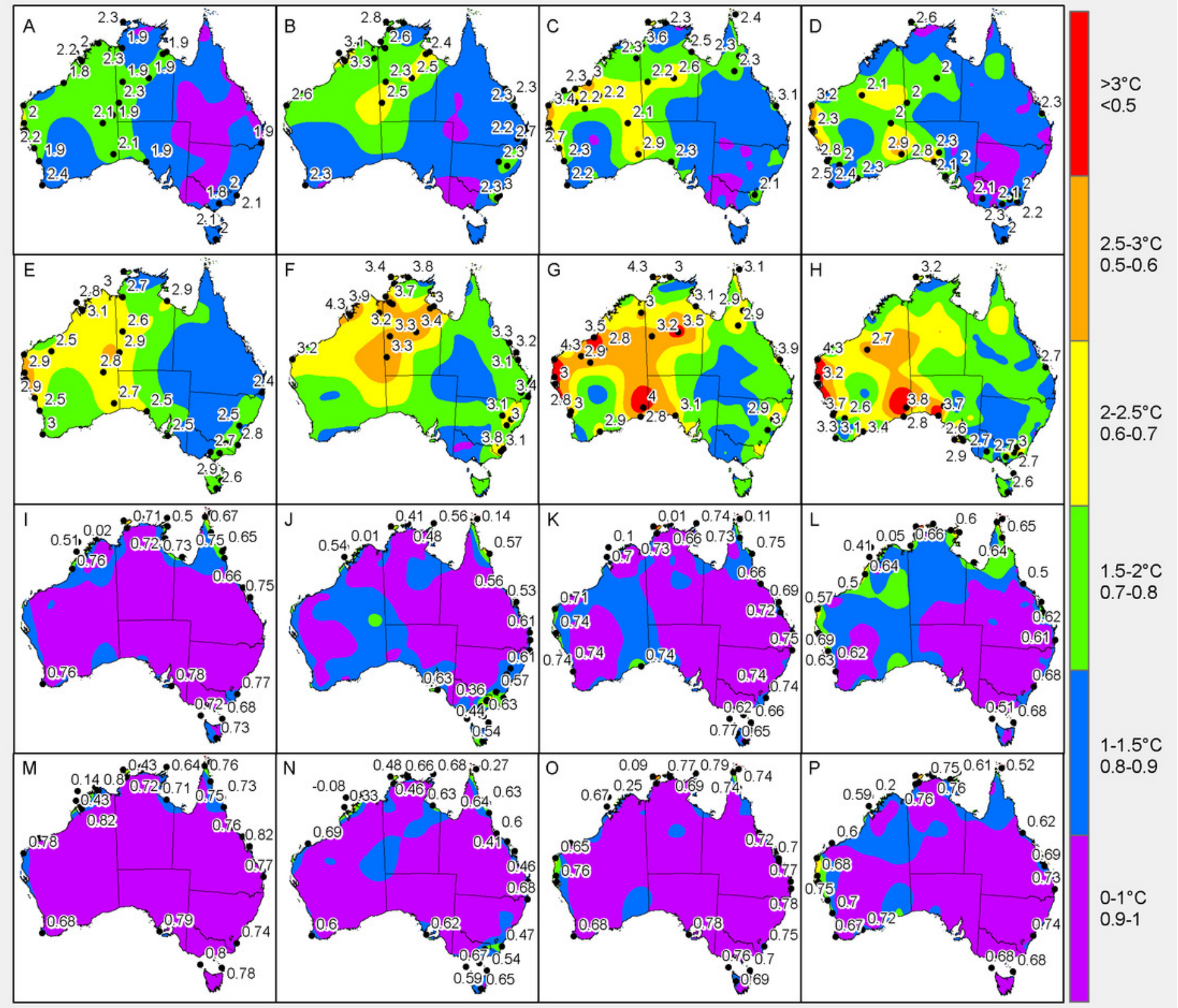




\section{Figure 5}

Interpolated MAE values (using a two-dimensional smoothing spline) according to each season and time of day.

(A) autumn, 12 am. (B) autumn, 3 am. (C) autumn, 6 am. (D) autumn, 9 am. (E) autumn, 12 pm. (F) autumn, 3 pm. (G) autumn, 6 pm. (H) autumn, 9 pm. (I) winter, 12 am. (J) winter, 3 am. (K) winter, 6 am. (L) winter, 9 am. (M) winter, 12 pm. (N) winter, 3 pm. (O) winter, 6 pm. (P) winter, 9 pm. (Q) spring, 12 am. (R) spring, 3 am. (S) spring, 6 am. (T) spring, 9 am. (U) spring, 12 pm. (V) spring, 3 pm. (W) spring, 6 pm. (X) spring, 9 pm. (Y) summer, 12 am. (Z) summer, 3 am. (AA) summer, 6 am. (BB) summer, 9 am. (CC) summer, 12 pm. (DD) summer, 3 pm. (EE) summer, 6 pm. (FF) summer, 9 pm.

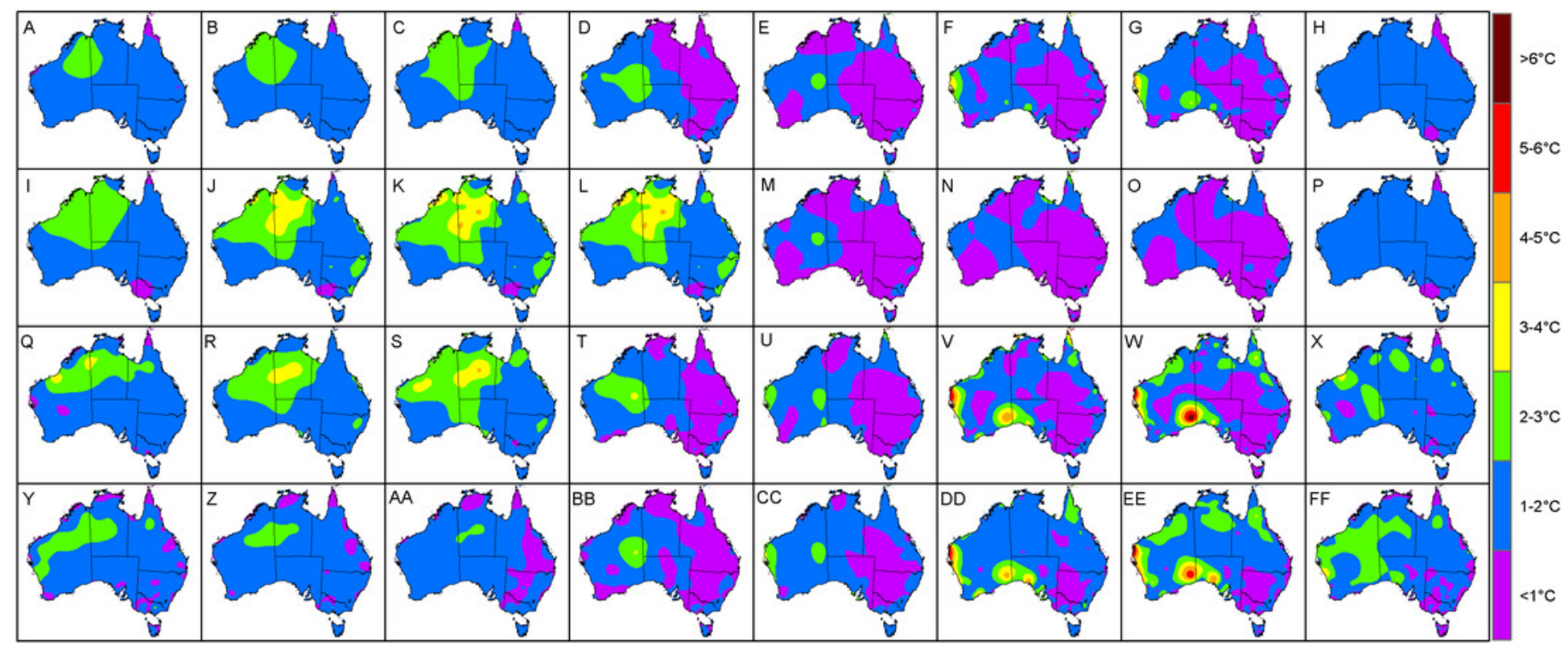




\section{Figure 6}

Interpolated RMSE values (using a two-dimensional smoothing spline) according to each season and time of day.

(A) autumn, 12 am. (B) autumn, 3 am. (C) autumn, 6 am. (D) autumn, 9 am. (E) autumn, 12 pm. (F) autumn, 3 pm. (G) autumn, 6 pm. (H) autumn, 9 pm. (I) winter, 12 am. (J) winter, 3 am. (K) winter, 6 am. (L) winter, 9 am. (M) winter, 12 pm. (N) winter, 3 pm. (O) winter, 6 pm. (P) winter, 9 pm. (Q) spring, 12 am. (R) spring, 3 am. (S) spring, 6 am. (T) spring, 9 am. (U) spring, 12 pm. (V) spring, 3 pm. (W) spring, 6 pm. (X) spring, 9 pm. (Y) summer, 12 am. (Z) summer, 3 am. (AA) summer, 6 am. (BB) summer, 9 am. (CC) summer, 12 pm. (DD) summer, 3 pm. (EE) summer, 6 pm. (FF) summer, 9 pm.

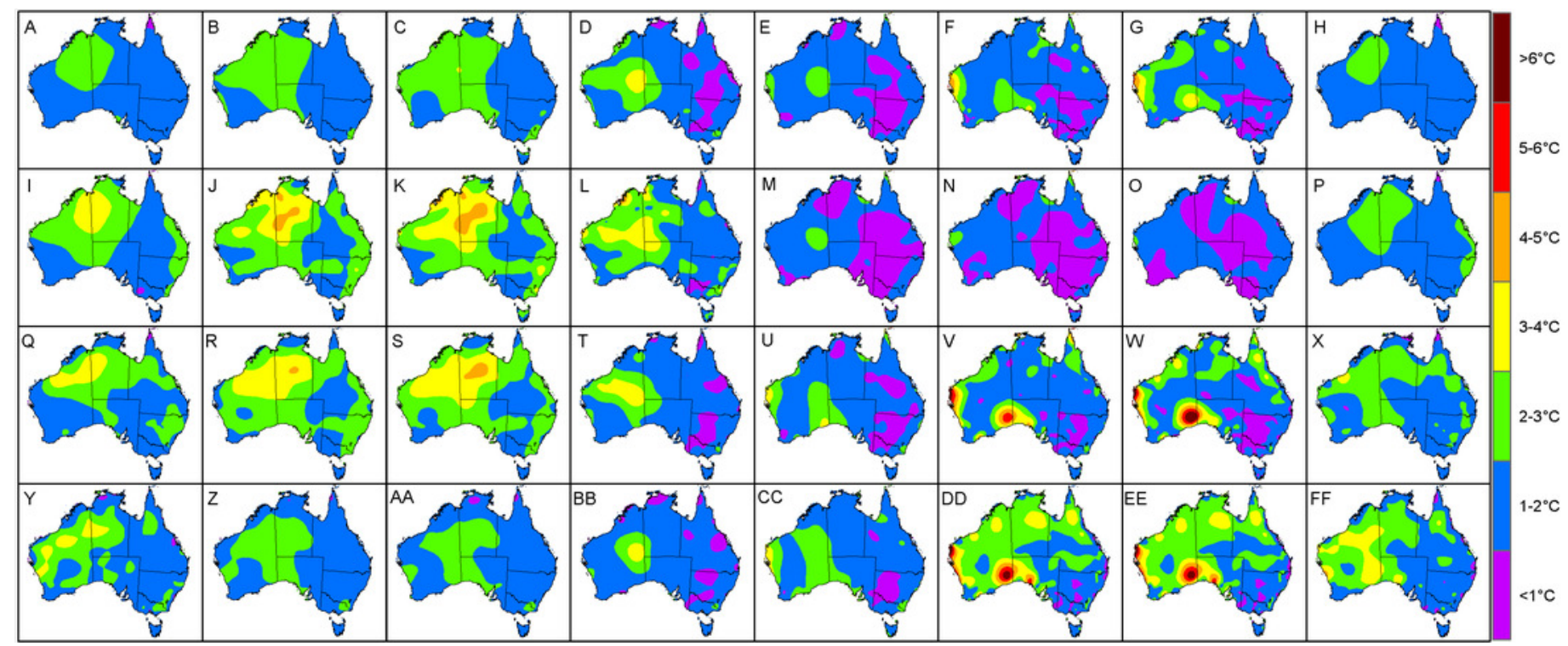


Figure 7

Line plots for selected AWS sites over a 24-hour period in each season for validation metrics concerning MAE, RMSE, $R^{2}$ and $P_{c}$.

(A) MAE in autumn. (B) MAE in winter. (C) MAE in spring. (D) MAE in summer. (E) RMSE in autumn. (F) RMSE in winter. (G) RMSE in spring. (H) RMSE in summer. (I) $R^{2}$ in autumn. (J) $R^{2}$ in winter. (K) $R^{2}$ in spring. (L) $R^{2}$ in summer. (M) $P_{c}$ in autumn. (N) $P_{c}$ in winter. (O) $P_{c}$ in spring.

(P) $P_{c}$ in summer.

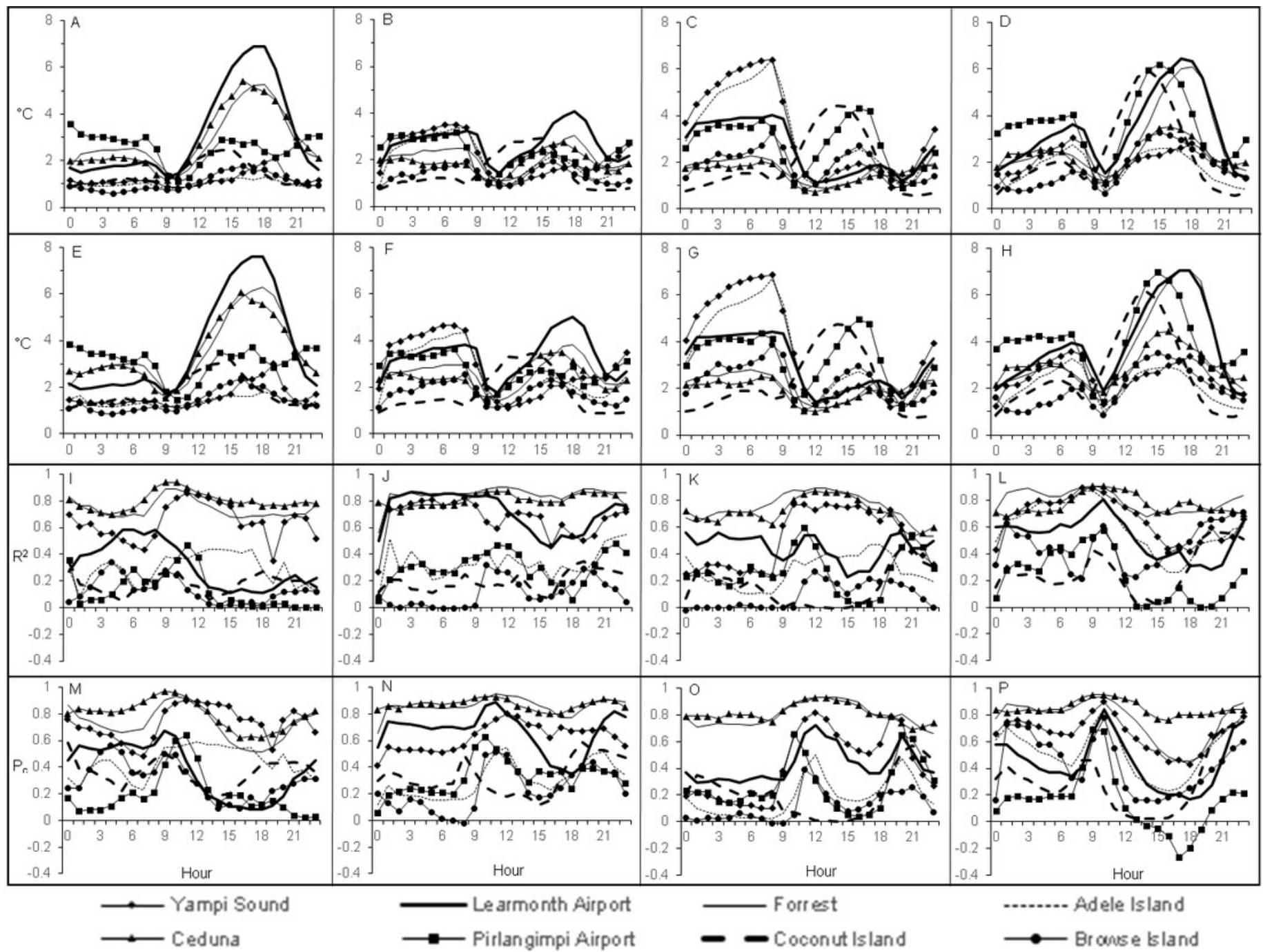




\section{Figure 8}

Interpolated $\mathrm{R}^{2}$ values (using a two-dimensional smoothing spline) according to each season and time of day.

(A) autumn, 12 am. (B) autumn, 3 am. (C) autumn, 6 am. (D) autumn, 9 am. (E) autumn, 12 pm. (F) autumn, 3 pm. (G) autumn, 6 pm. (H) autumn, 9 pm. (I) winter, 12 am. (J) winter, 3 am. (K) winter, 6 am. (L) winter, 9 am. (M) winter, 12 pm. (N) winter, 3 pm. (O) winter, 6 pm. (P) winter, 9 pm. (Q) spring, 12 am. (R) spring, 3 am. (S) spring, 6 am. (T) spring, 9 am. (U) spring, 12 pm. (V) spring, 3 pm. (W) spring, 6 pm. (X) spring, 9 pm. (Y) summer, 12 am. (Z) summer, 3 am. (AA) summer, 6 am. (BB) summer, 9 am. (CC) summer, 12 pm. (DD) summer, 3 pm. (EE) summer, 6 pm. (FF) summer, 9 pm.

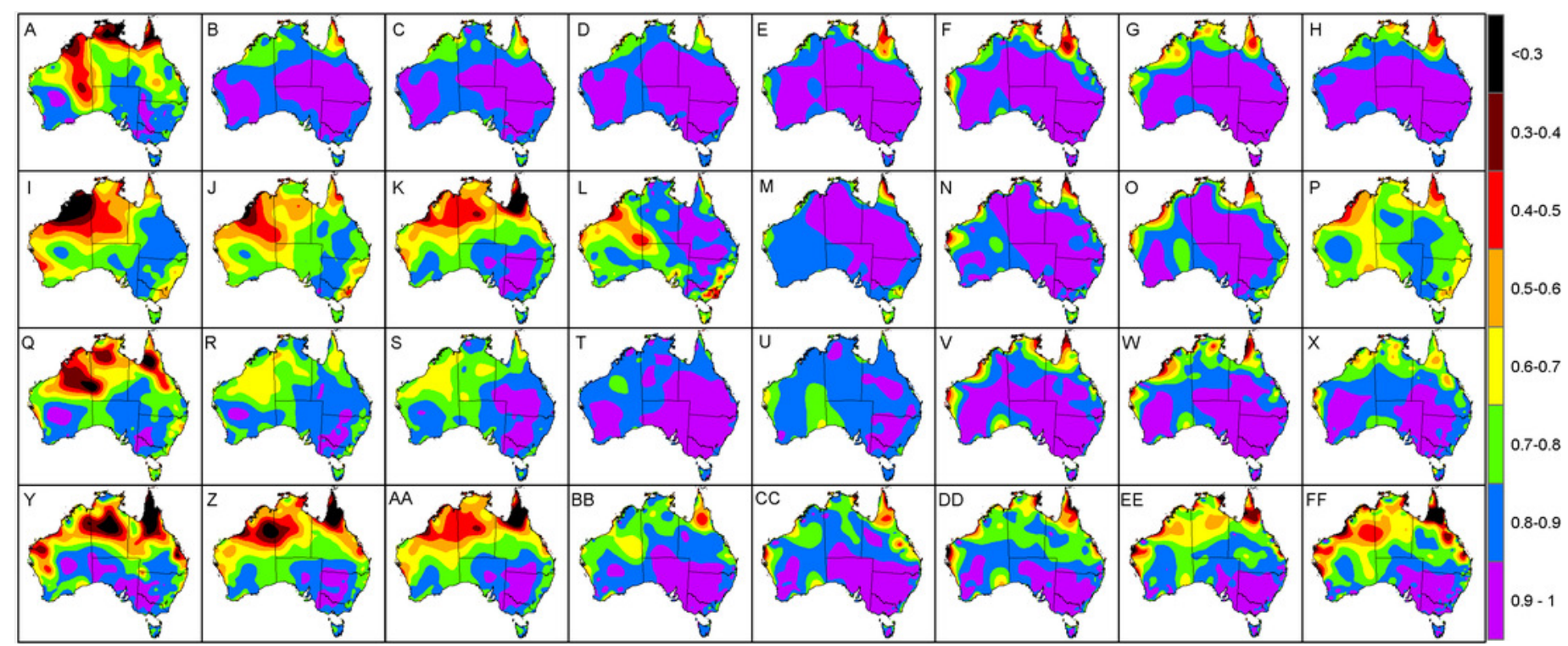




\section{Figure 9}

Interpolated $\mathrm{P}_{\mathrm{c}}$ values (using a two-dimensional smoothing spline) according to each season and time of day.

(A) autumn, 12 am. (B) autumn, 3 am. (C) autumn, 6 am. (D) autumn, 9 am. (E) autumn, 12 pm. (F) autumn, 3 pm. (G) autumn, 6 pm. (H) autumn, 9 pm. (I) winter, 12 am. (J) winter, 3 am. (K) winter, 6 am. (L) winter, 9 am. (M) winter, 12 pm. (N) winter, 3 pm. (O) winter, 6 pm. (P) winter, 9 pm. (Q) spring, 12 am. (R) spring, 3 am. (S) spring, 6 am. (T) spring, 9 am. (U) spring, 12 pm. (V) spring, 3 pm. (W) spring, 6 pm. (X) spring, 9 pm. (Y) summer, 12 am. (Z) summer, 3 am. (AA) summer, 6 am. (BB) summer, 9 am. (CC) summer, 12 pm. (DD) summer, 3 pm. (EE) summer, 6 pm. (FF) summer, 9 pm.

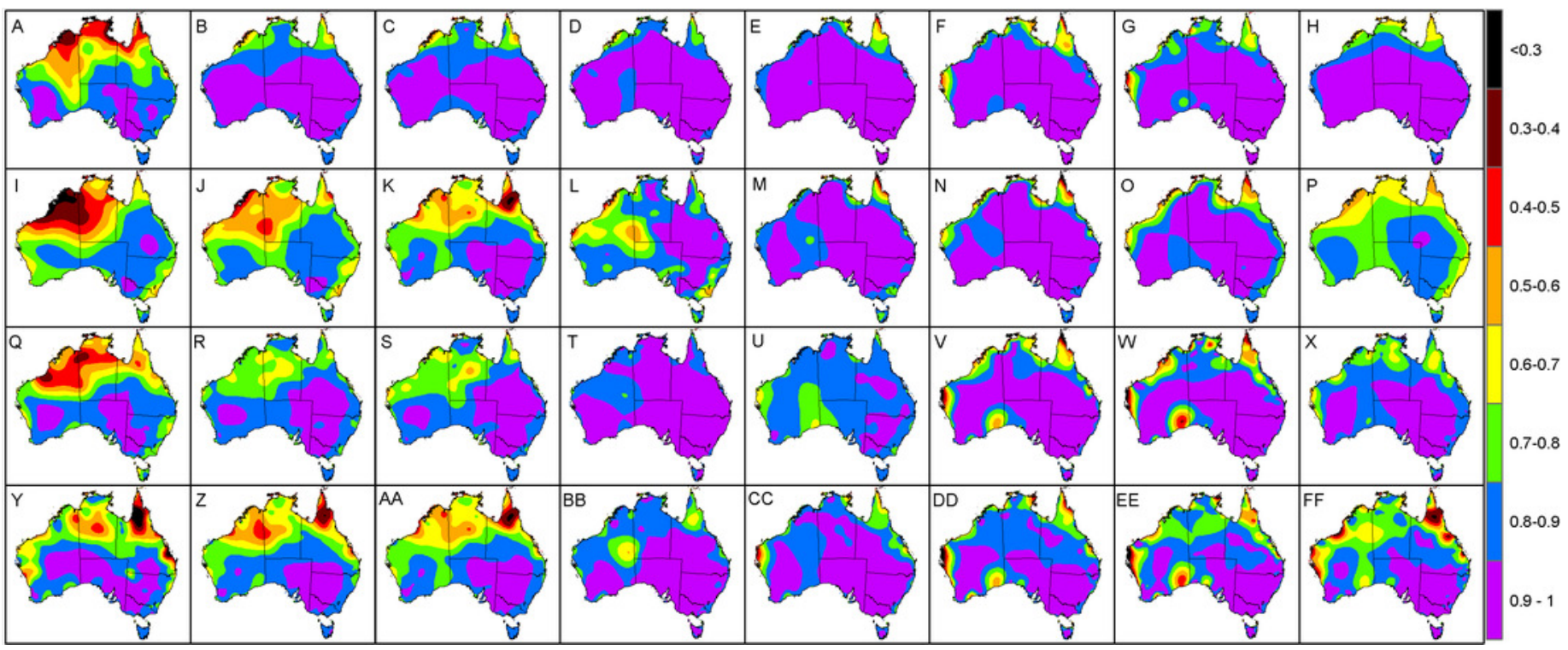




\section{Figure 10}

Frequency of map completion times (minutes from AWS observation time, $T$ ) in accordance to their bi-hourly processing intervals.
(A) 0 minutes. (B) 30 minutes.

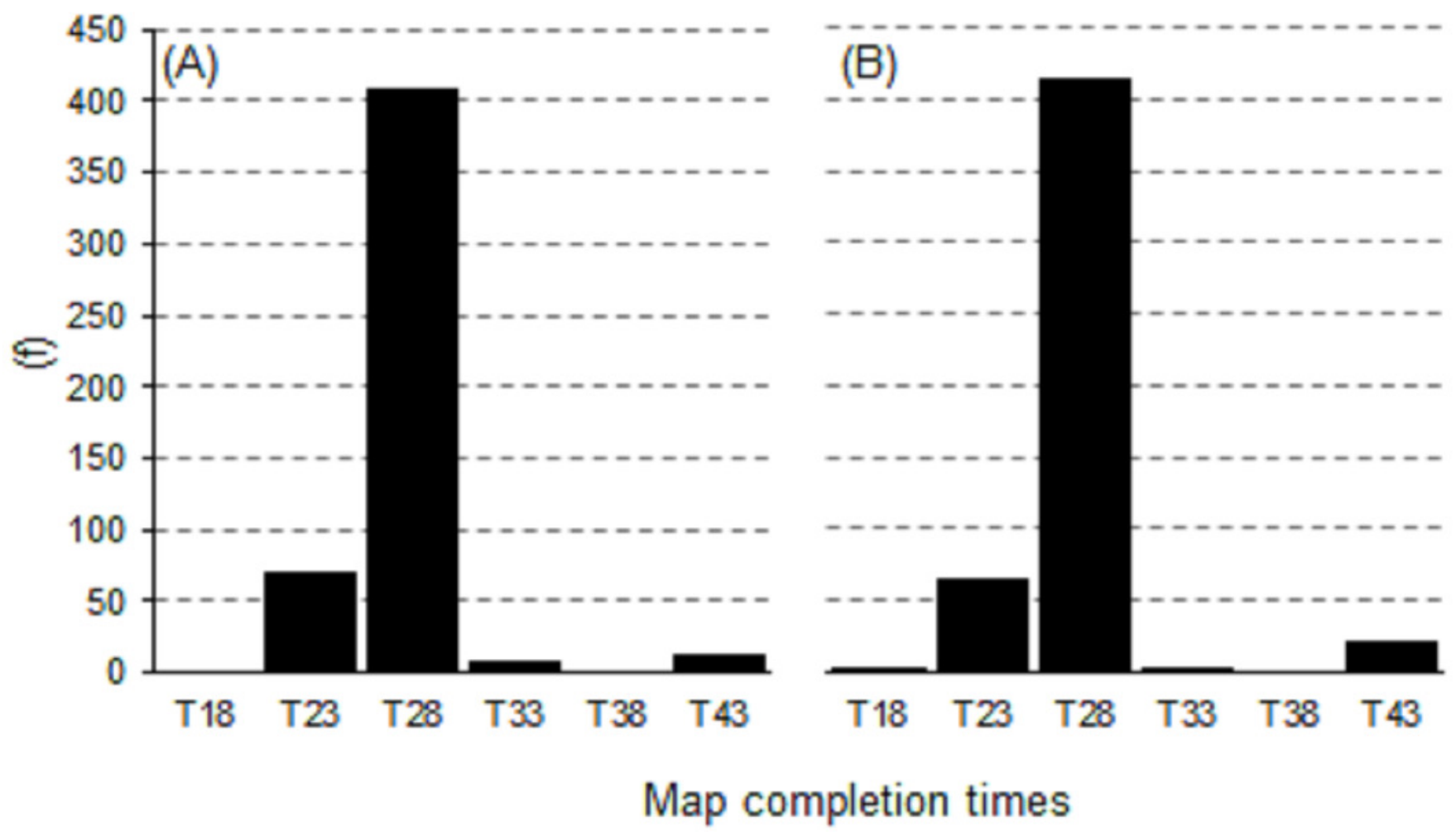


Figure 11

Box and whisker plots for AWS import times (minutes from AWS observation time, T) in accordance to their bi-hourly processing intervals.

(A) 0 minutes. (B) 30 minutes. Numbers in bold denote frequencies when the 480 observation threshold limit was reached.

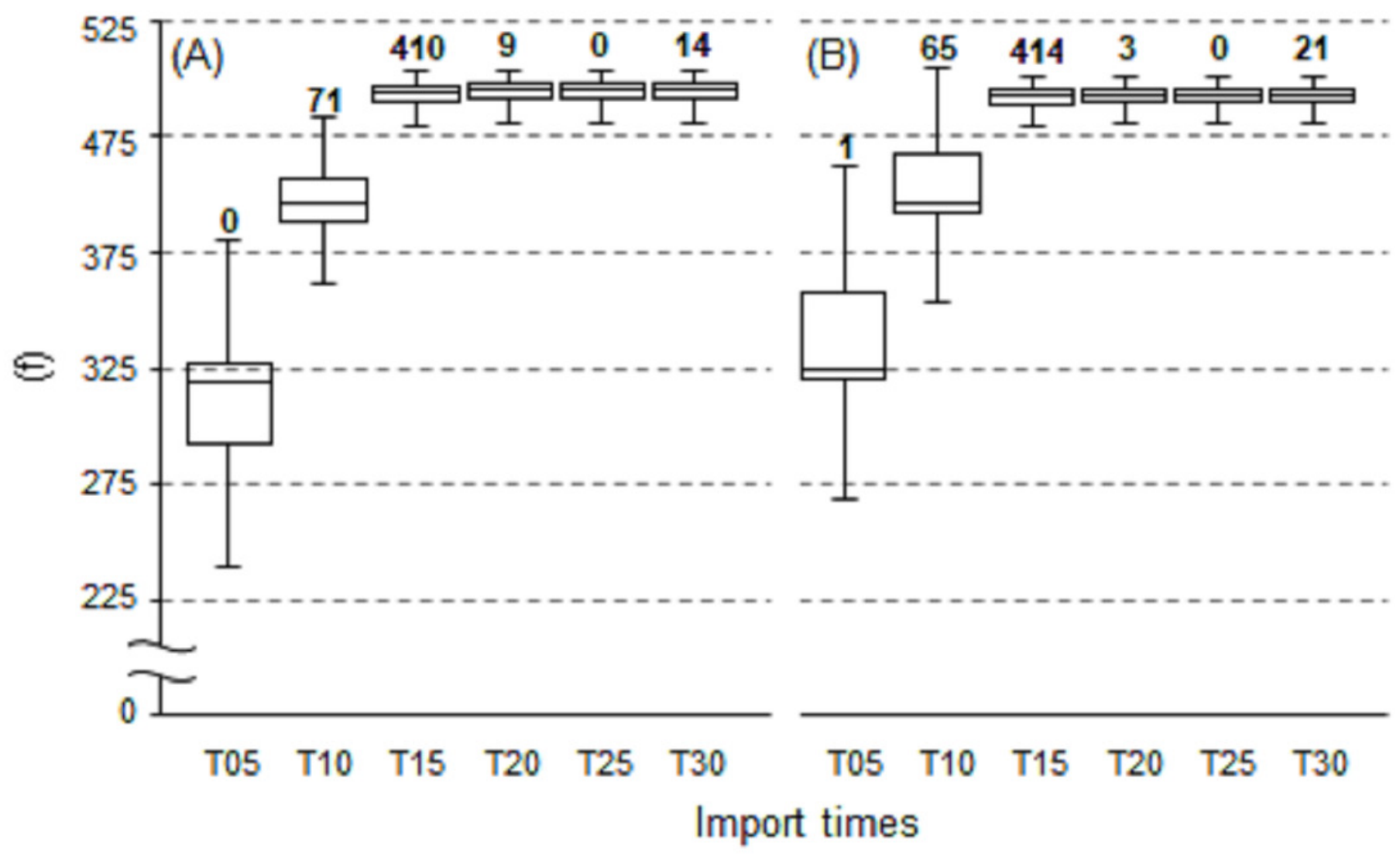




\section{Figure 12}

Web map environment for displaying and spatially interrogating the near real-time $T_{a}$ outputs. An example can be viewed at URL http://austemperature.live/.

(c) OpenStreetMap contributors, CC BY SA

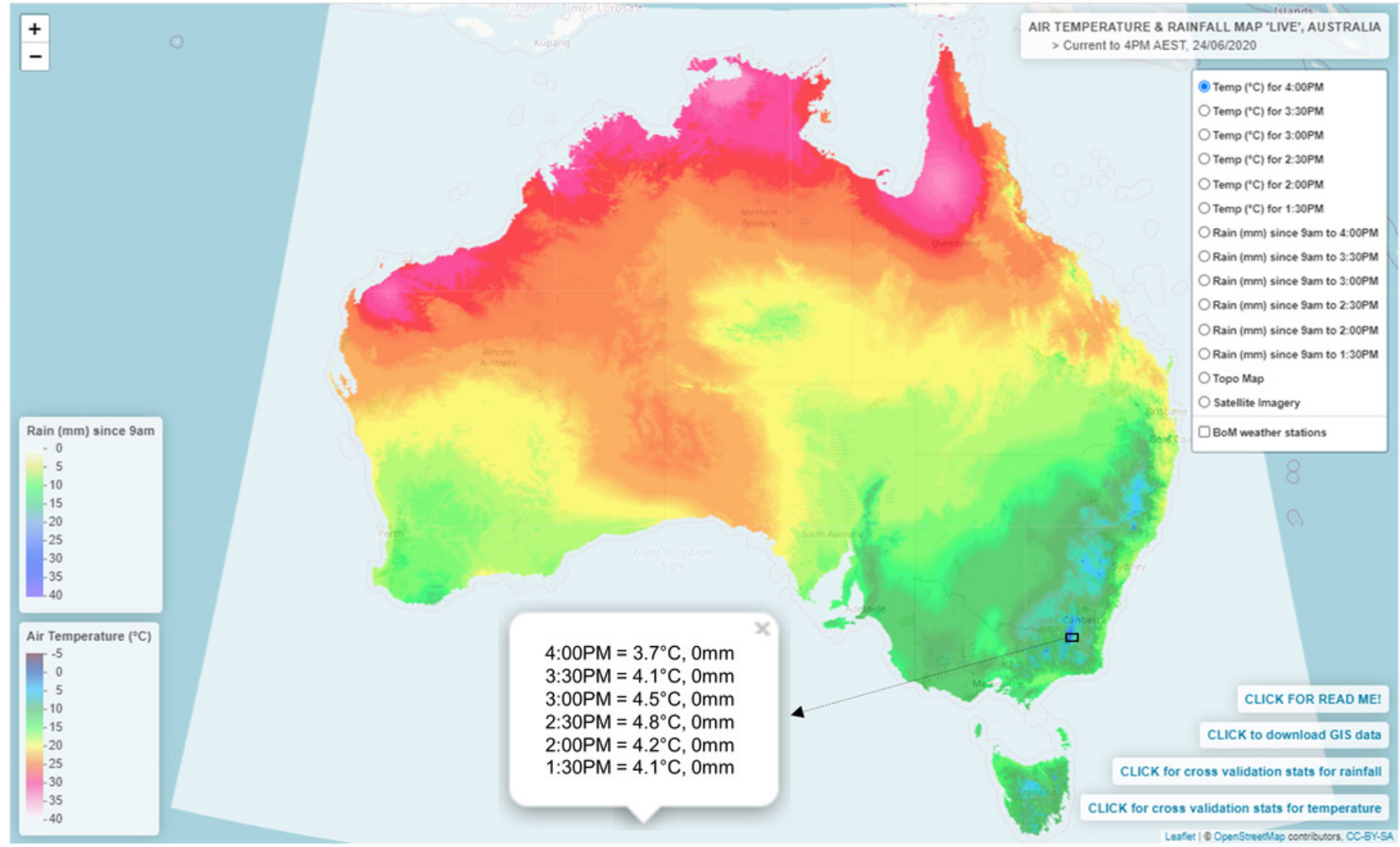




\section{Table 1 (on next page)}

Validation statistics for the TPS interpolation procedure showing $R^{2}, P_{c}, \operatorname{MAE}\left({ }^{\circ} \mathrm{C}\right)$ and RMSE $\left({ }^{\circ} \mathrm{C}\right)$ values - averaged for each AWS site according to the season.

sd standard deviation, min minimum, max maximum 


\begin{tabular}{ccccc}
\hline & Summer & Autumn & Winter & Spring \\
\hline $\mathrm{R}^{2}$ & & & & \\
mean & 0.89 & 0.91 & 0.86 & 0.91 \\
min & 0.05 & 0.02 & 0.01 & 0.01 \\
max & 0.99 & 0.99 & 0.97 & 0.99 \\
sd & 0.11 & 0.09 & 0.11 & 0.09 \\
$P_{\text {c }}$ & & & & \\
mean & 0.92 & 0.94 & 0.92 & 0.93 \\
min & 0.18 & 0.14 & 0.18 & 0.09 \\
max & 0.99 & 0.99 & 0.99 & 0.99 \\
sd & 0.09 & 0.08 & 0.09 & 0.08 \\
MAE & & & & \\
mean & 1.2 & 1.2 & 1.3 & 1.3 \\
min & 0.5 & 0.5 & 0.5 & 0.6 \\
max & 3.2 & 2.8 & 3.3 & 3.6 \\
sd & 0.4 & 0.4 & 0.5 & 0.5 \\
$\mathrm{RMSE}$ & & & & \\
mean & 1.6 & 1.6 & 1.7 & 1.7 \\
min & 0.6 & 0.7 & 0.7 & 0.8 \\
max & 4.3 & 3.5 & 4.3 & 4.3 \\
sd & 0.5 & 0.5 & 0.6 & 0.6 \\
\hline
\end{tabular}

1 


\section{Table 2 (on next page)}

K-fold cross-validation statistics for the TPS interpolation procedure showing $R^{2}, P_{c}$, MAE $\left({ }^{\circ} \mathrm{C}\right)$ and RMSE $\left({ }^{\circ} \mathrm{C}\right)$ values - averaged for each season.

sd standard deviation, min minimum, max maximum 


\begin{tabular}{ccccc}
\hline & Summer & Autumn & Winter & Spring \\
\hline $\mathrm{R}^{2}$ & & & & \\
mean & 0.93 & 0.92 & 0.9 & 0.92 \\
min & 0.4 & 0.43 & 0.04 & 0.41 \\
max & 0.99 & 0.99 & 0.99 & 0.99 \\
sd & 0.04 & 0.05 & 0.07 & 0.06 \\
$P_{\text {c }}$ & & & & \\
mean & 0.96 & 0.96 & 0.95 & 0.96 \\
min & 0.62 & 0.62 & 0.19 & 0.63 \\
max & 1 & 1 & 1 & 1 \\
sd & 0.02 & 0.03 & 0.04 & 0.03 \\
MAE & & & & \\
mean & 1.2 & 1.2 & 1.3 & 1.3 \\
min & 0.5 & 0.5 & 0.4 & 0.5 \\
max & 2.7 & 2.5 & 3 & 3.1 \\
sd & 0.3 & 0.3 & 0.4 & 0.4 \\
$\mathrm{RMSE}$ & & & & \\
mean & 1.7 & 1.6 & 1.7 & 1.8 \\
min & 0.7 & 0.6 & 0.5 & 0.7 \\
max & 6.4 & 7.6 & 10 & 7.4 \\
sd & 0.4 & 0.4 & 0.6 & 0.5 \\
\hline
\end{tabular}

1 